\title{
AN ASSESSMENT INSTRUMENT FOR THE "ANALYSIS AND PROBLEM SOLVING" COMPETENCE: CONTEXT AND RESULTS
}

\author{
Pedro Gómez-Gasquet, María-José Verdecho, Raúl Rodríguez-Rodríguez, Juan- \\ José Alfaro-Saiz \\ Department of Business Organization, Universitat Politècnica de València (SPAIN)
}

\begin{abstract}
In the last years, there is an increasing interest in the manner that transversal competences (TC) are introduced in the curricula. Transversal competences are generic and relevant skills that students have to develop through the several stages of the educational degrees. This paper explain the context of TC in Higher Studies at the Universitat Politècnica de València (UPV), Spain, where several working groups have been established in the last three years in order to improve the way both Technical Schools and lecturers/professors teach and assess the degree of development of transversal competences (TC) in students. The UPV has promoted to grant various innovative educational projects that contribute to improve the assessment and collection of evidences on TC. This paper emerges from the work developed in one of these innovative educational projects and presents the experience related to the assessment of the TC "analysis and problem solving". The main aim of this paper is to analyse the assessment of analysis and problem solving in the context of postgraduate programmes at the UPV and, according to them, to develop and apply an assessment instrument. The developed assessment instrument comprises the relevant indicators to assess the students written communication competency. It has been applied to evaluate the assignments of students in the course named "Production planning and scheduling in distributed environments", which belongs to the Master Degree in Advanced Engineering Production, Logistics and Supply Chain at the UPV. This paper presents both the educational experience and main results obtained.
\end{abstract}

Keywords: Transversal competences, university, technical programmes, master degree, assessment instrument.

\section{THE CONTEXT OF UNIVERSITAT POLITÈCNICA DE VALÈNCIA}

As part of the new degrees and the change of educational models inherent to the process of European Convergence [1], generic competences acquire a very important role.

Universities and institutions of higher education are constantly faced with the challenges of preparing students for a better understanding of their environment and thus to increase their employability. The training system needs therefore to focus on providing a consistent basis for both specific skills [2] as well as transverse frame, where it is of key importance not only the ability to innovate but also the ability to adapt quickly and effectively to changes in use and constantly upgrading the skills required in their working lives.

The number of transversal competences that can work in higher education is elevate and can be grouped by type, as it can be seen in different proposals. The Institute for Education Science (IESwww.ice.upv.es) is in charge of helping teaching, providing training, support and advising to academic staff at the UPV. It is currently in charge of coordinate several actions to configure the response of the UPV to this new need. UPV's Transversal Competencies seek to synthesize the skills profile that all students acquire [3]. In addition, to ensure that the framework regulations degrees with some specific recommendations or covered as IES explain are met. IES has proposed thirteen TC, those are the following:

\begin{tabular}{|l|l|}
\hline TC-1 Understanding and integration & TC-8 Effective communication \\
\hline TC-2 Application practical thinking & TC-9 Critical thinking \\
\hline TC-3 Analysis and problem solving & TC-10 Knowledge of contemporary issues \\
\hline TC-4 Innovation, creativity and entrepreneurship & TC-11 Continuous learning \\
\hline
\end{tabular}




\begin{tabular}{|l|l|}
\hline TC-5 Project design & TC-12 Planning and time management \\
\hline TC-6 Teamwork and leadership & TC-13 Instrumental specific \\
\hline TC-7 Professional and ethical responsibility & \\
\hline
\end{tabular}

The aim of this paper is to reflect the advances reached with an Educational Innovation and Improvement Project (PIME) carried out at the UPV. Focusing on the writing regarding the transversal competence 3 of analysis and problem solving, it is partially improved. In addition, it should be noted that the targeted sample to be assessed are students enrolled in the Master of Advanced Engineering Production, Logistics and Supply Chain (MUIAPLCS). This is an official postgraduate degree offered at the UPV and integrated into the PhD program on Industrial Production Engineering. This master already has more than 11 editions in which students address a set of both general and specific skills during the 60 ECTS credits of the programme.

The need to update assessment methods in the context of the Master is explained in section 2. A tool to evaluate the analysis and problem solving competence has been developed and is presented in section 3 . Finally, in section 4 , some guidelines are introduced and the results of an experimental application carried out during the academic course 2015/16 are commented.

\section{EMERGING NEEDS IN THE EVALUATION PROCESS}

The MUIAPLCS has developed and incorporated different tools for measuring both general and specific competences that were included in its curriculum. Tools were developed by different lecturers and coordinated by the Academic Committee. These tools have addressed complex issues such as workgroup tasks, which entail a high volume of the evaluation techniques employed. These types of evaluation, and others, have taken into account aspects currently known as transversal competences and not considered in the master curriculum at the beginning. The challenge posed is thus to identify differentially each transversal competence and create appropriate new tools for their evaluation [4].

The ability to analyse and solve problems is one of the skills intrinsically linked to technical studies such as engineering. And the truth is that in many subjects is addressed intensively and systematically. However, the transversal competences project offers the possibility of addressing this capacity individually. The resolution of a problem on an exam or an class exercise when only the final result is analysed leaves in the background multiple indicators of skills that ultimately may or may not be taken into account.

According to my working group the interest of analyses one of the capabilities that are more intensely addressed it is the possibility to give students disaggregated information on how to deal with it and at the same time force to take into account all these aspects that are necessary to develop with the best practices.

After several discussions under the PIME project, it was agreed that a way to unify criteria and to obtain the expected results in a short period of time was the design and implementation of a scoring rubric adapted to measuring analysis and problem solving competence. The lack of previous culture on transversal competence analysis represented the major issue when creating a tool that simultaneously helps to describe the concept itself and to provide a score to students. In addition, it should be useful to both lecturers and students. Likewise, the implementation of a rubric is simple, as it requires minimal explanations, it is also easy to distribute and does not require complex help for completing it.

Another relevant aspect is that rubrics have a reduced degree of flexibility, favouring a very similar interpretation regardless of either the subject evaluated or evaluator. It is not a pure objective instrument, but helps to reduce subjectivity greatly.

\section{RUBRIC PROPOSED: STRUCTURE AND MEASUREMENT}

The use of scoring rubrics as the measurement method has different considerations [5]. In order to design a rubric for the transversal competence on effective written communication, a team was built and considered the following objectives:

1 Rubric must be applicable in a context of either high or low number of students. 
2 Rubrics should be possible to use in different subjects and programs.

3 Rubric should avoid ambiguity.

4 Rubric should help to differentiate the students evaluated at least in 3 groups (Target achieved, on track to meet the target, target not achieved). Introducing least possible error.

5 Rubric must be, if it is considered, a self-assessment tool.

6 Rubric should chart data easily in a 1-10 scale.

From the above conditions, and analysing previous work carried out by IES [6] some specific constraints that will help to achieve the overall objectives raised.

a) A scale of 1-4 should be considered in the scoring of different dimensions, as it is reduced but improves the accuracy of 1 to 3 scale. It helps to achieve objective 4 .

b) The number of dimensions to be evaluated should be up to 10 , if possible, divided into blocks. It helps to achieve the objectives 1, 3, 4 and 5 .

c) Four thematic sections will be established: One block to analyse the causes and effects of problems from a global long-term approach, one block to evaluate the advanced search criteria information for troubleshooting and evaluates the quality of information, one block to evaluate the systematic way to work, and finally one block to evaluates possible solutions as viable scientific and technical difficulty of implementation. It helps achieve the objectives 3 and 5 and according to the general criteria set by UPV [6].

d) It will be included a table to pick up one or more students. It helps to achieve the objective 1 and 5.

As presented in Annex I, where the proposed rubric is shown, four blocks have been established according to the suggestion made by [6] for the assessment of this competence in the level corresponding with postgraduate course. In each block they are taken into account between 2 and 3 dimensions.

The rubric should allow us to reach from the corresponding workgroup result to the individual rating. To do this rubric is used whenever focusing initially on group analysis, either exhibitions or written documents, and subsequently adapted on individual qualifications. The elements for group evaluation are primarily documentary. For individual assessment uses observation for the development of work in classes and direct questions to students after oral communication.

The rating on the scale is qualitative, and can be: A Excellent, Good B, C or D Developing unreached. In the group stage evaluation it is not necessary to add the rating to the head of the blocks. And it is taken as the benchmark for individual assessment.

After the group evaluation, all individual evidence is collected and group value will be adapted to the individual, dimension by dimension. It is not recommended that the variation is greater than one step. Once all the individual dimensions have been filled, blocks should be evaluate and attach the rating on its head. This rating must ensure that reflects true state of the dimension according to [6], and not obtained quantitatively. Similarly, the qualification of the competence should be the overall assessment of the skills achieved in each block.

\section{GUIDELINES, RESULTS ACHIEVED AND CONCLUSIONS}

\subsection{Guidelines for rubric use}

The rubric is a fixed picture of the state of analysis and problem solving competence in a subject. However, transversal competences should be analyzed throughout the lifecycle of the student in the program. In other words, the scoring obtained in a transversal competence at a particular time should not be conclusive but guidance. Among other aspects, the assessment is affected by the state of the evaluator and evaluated, type of material, or type of act of evaluation in which it occurs. All these issues should be reduced within the design of the rubric. Therefore, the best guarantee to ensure a good assessment is repetition.

Although, this paper focuses on the rubric as a tool, it should not stop of paying attention to its ultimate goal: evaluation. In this sense, the selection of several subjects within the degree (checkpoints) separated in time is proposed (e.g. year 2 and year 4, semester A or semester B). With the scores 
obtained in these subjects, programme responsible could observe the evolution of students, scheduling at least 3 subjects as checkpoint. Thus, the second score indicates responsible the evolution of the student and corrective plans could be implement before the third and final assessment. It is also proposed to perform various evaluations within the same subject. These repetitions allow analyse written competence in different contexts (work, short answer, etc.), which enables a more contrasted score based on a final average.

In this guide, we would highlight he importance of communication with students in the evaluation process. The student should be familiar with the rubric, or what it is the same: about what it is being evaluated and the process itself. It should help each actor to focus on what it is important and to know that what is being tested is an acquired habit.

\subsection{Results reached}

Once the rubric was designed, it was used experimentally in a specialty course in the second semester called Production Planning and Scheduling in Distributed Environments (PPPED). The selected subject is taught once students have already completed half of the course. However, due to the program ERASMUS, new enrolled students during the course of study are a normal fact. This subject is divided into blocks. At a first stage, in students work on more conceptual issues, where they receive more than generate, and a second phase in which the practical aspects are predominant. As a subject of research-oriented specialty rather than the professional-oriented, the number of students is very small. In this case there were 9 enrolled students. The scoring of the course was based on several evaluations process but it takes a very important role the development of a final work in scientific paper format. This form of expression is a novelty and a challenge for students used to work with an academic rather than scientific format. In this work, students must combine a series of previous learning and carry out a reasoned but synthetic presentation of their proposals and achievements. It is therefore very important for students to use an excellent problem analysis and definition, literature review, problems solving and results analysis.

As regards the implementation of the evaluation, as recommended in the guideline, the rubric was used in different kinds of acts of evaluation: a case and course work. The first assessment was carried directly out by lecturer on the material used for the presentation of previously raised cases. It was PowerPoint documents that students developed. The second application was applied to a written scientific format paper developed by the students form a single group. This paper was defended in a public oral exposition. It is important to notice that in the first test, students were not previously aware of the existence of the rubric while in the second test they knew about it.

Lecturers said that after inform about the assessment of analysis and problems solving and explain the rubric had detected a qualitative step forward in that competence. It is reflected in the following data:

Table. 1 - Average and standard deviation for test 1 and test 2 in each group dimension.

\begin{tabular}{|l|l|l|l|l|l|l|}
\hline & \multicolumn{3}{|c|}{ Test 1 } & \multicolumn{3}{|c|}{ Test 2 } \\
\hline & A & B & C & A & B & C \\
\hline Analyses the causes and effects of problems from a global long-term approach & 4 & 4 & 1 & 6 & 2 & 1 \\
\hline $\begin{array}{l}\text { Applies advanced search criteria information for troubleshooting and evaluates the } \\
\text { quality of information }\end{array}$ & 2 & 6 & 1 & 8 & 1 & 0 \\
\hline Organized in a systematic way to work decision & 3 & 5 & 1 & 7 & 2 & 0 \\
\hline $\begin{array}{l}\text { Evaluates possible solutions as viable scientific and technical difficulty of } \\
\text { implementation }\end{array}$ & 4 & 5 & 0 & 7 & 2 & 0 \\
\hline
\end{tabular}

Note: Each column shows the number of students with the corresponding level (A, B or C). Level D is not observed.

Additionally, in order to improve our perception about the opinion of the students in using the rubric, we surveyed them after the course was finished. It was asked the following:

- Is the evaluation procedure adequate?

- Is the assessment instrument suitable? 
- Is the overall satisfaction with the evaluation appropriate?

The first three questions were evaluated between 1 and 10 , while the latter was purely qualitative. The average results obtained were $8,8.5$ and 8 respectively. It should be added that the score of the subject achieved by students were slightly higher than other courses.

\subsection{Conclusions}

After completing the experimental application and collect the data and the perceptions some lessons have been drawn. The conclusions reflected here are not the results of a design of experiments being therefore qualitative.

First, it showed how students and lecturers focused part of its efforts on thinking about the contribution of the analysis and problem solving competence in the subject and its relevance in the programme.

Second, it resulted in a debate that helped both students and lecturers to define the scope of analysis and problem solving competence and the most important aspects of it.

In third place was reflected, as it was known, that students focused their efforts much better when they knew what it was measured, allowing identify areas of improvement. In this case, they knew the scoring of test 1 in the different dimension of the rubric before carrying out the test 2 .

Fourth, it was detected how the students may be assessed on whether a subject is checkpoint in too many transversal competences.

On the other hand, although it could not be checked in the experiment, it seems reasonable to consider that the rubric that is used in transversal competences must have the feature of portability between subjects unlike the specific competences. However, the problem of the evaluation of transversal competences is much more complex than designing a rubric. Among other considerations it should take into account how to combine the assessment of the 13 transversal competences without generating over assessment and getting along student life in programme reliable measurements.

\section{ACKNOWLEDGEMENTS}

This work has been developed within the research project called "Assessment of UPV generic competence "problem analysis and resolution" in master students" (Ref.: PIME-A7-15) funded by the Vice-Rectorate for Studies, Quality and Acreditation <https://www.upv.es/entidades/VECA/indexen.html> at Universitat Politècnica de València.

\section{REFERENCES}

[1] Gonzalez, J. and Wagenaar R. (2008). Universities' contribution to the Bologna process. An introduction. 2nd Edition Tunning Project, Publicaciones de la Universidad de Deusto. ISBN 978-84-9830-132-8.

[2] Gonzalez, J. and Wagenaar R. (2008). Reference Points for the design and delivery of degree programmes in European studies. Tunning Project, Publicaciones de la Universidad de Deusto.

[3] Laguarda N., Conesa, C., Ibañez, J., García, E., Gil, L., and Montes, R. (2015). Promoting transversal competences in final degree projects: Some experiences at the UPV. $9^{\text {th }}$ International technology, education and development conference, pp. 4531-4535, IATED ISBN 978-84-606-5763-7.

[4] Kingston, N., Nash, B. (2011). Formative Assessment: A meta-analysis and call for research. Educational Measurement: Issues and Practice, Educational Measurement: Issues and Practice 30(4). 28-37.

[5] Sonseca, A., Sahuquillo, O., Martinez-Casas, J., Carballerira, F. and Rodenas J.J. (2015). Assessment of oral and written communication competences in the European Higher Education Area: a proposal of evaluation methodologies. Head' $151^{\text {st }}$ International conference on higher education advances. Editorial UPV.

[6] Proyecto de competencias transversales de la UPV. Download at http://www.upv.es/entidades/ICE/info/U0724624.pdf on June 30th 2016. 


\section{ANNEX I - RUBRIC TEMPLATE}

\section{ANALYSIS AND SOLVING PROBLEM COMPETENCE - EVALUATION TOOL FOR WORKGROUP IN MÁSTER PROGRAMME. SUBJECT PPPED.}

Write in the table below the name of students and grade them according to the level $(A-D)$ that best describes the performance of each person in the corresponding column number. Follow the instructions below.

\begin{tabular}{|c|l|}
\hline $\mathbf{N}^{\circ}$ & Group members \\
\hline 1 & \\
\hline 2 & \\
\hline 3 & \\
\hline
\end{tabular}

Level D - Not reached Level C - Developing Level B - Good Level A - Excellent

\begin{tabular}{|c|c|c|c|c|c|}
\hline & & 1 & 2 & 3 & GROUP \\
\hline & $\begin{array}{l}\text { Analyses the causes and effects of problems from a global } \\
\text { long-term approach }\end{array}$ & & & & \\
\hline 1 & Sets the context of the problem & & & & \\
\hline \multirow[t]{2}{*}{2} & $\begin{array}{l}\text { Defines the problem to solve describing clearly and concisely the } \\
\text { facts (data) and most important variables }\end{array}$ & & & & \\
\hline & $\begin{array}{l}\text { Applies advanced search criteria information for } \\
\text { troubleshooting and evaluates the quality of information }\end{array}$ & & & & \\
\hline 3 & Validates the model or contrast the data problem & & & & \\
\hline 4 & Generalizes or extends the problem & & & & \\
\hline \multirow[t]{2}{*}{5} & Analyses valuable literature & & & & \\
\hline & Organized in a systematic way to work decision & & & & \\
\hline 6 & Establishes a scientific system to analyse and propose solutions & & & & \\
\hline \multirow[t]{2}{*}{7} & Learned methods are adapted to the case & & & & \\
\hline & $\begin{array}{l}\text { Evaluates possible solutions as viable scientific and } \\
\text { technical difficulty of implementation }\end{array}$ & & & & \\
\hline 8 & The solution is clearly exposed & & & & \\
\hline 9 & The solution is adapted to be used in a real environment & & & & \\
\hline 10 & Proposes alternative solutions & & & & \\
\hline
\end{tabular}

\section{Instructions}

1. Evaluate first disaggregate aspect of each block of the group column.

2. Transfer group column values to individual columns, modifying one up or down the current value o remains it.

3. Apply the average rating (qualitative) at the head of each block of the individual columns. 